\title{
Diazotrophic bacteria and substrates in the growth and nitrogen accumulation of
}

\section{sugarcane seedlings}

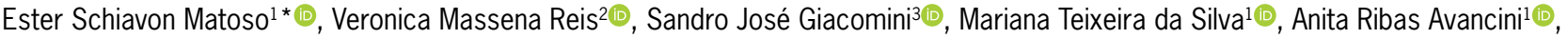 \\ Sérgio Delmar dos Anjos e Silva ${ }^{4}{ }^{\circ}$
}

\author{
'Universidade Federal de Pelotas/FAEM, Av. Eliseu Maciel - \\ 96010-900 - Capão do Leão, RS - Brasil. \\ 2Embrapa Agrobiologia, BR 465, km 7 - 23891-000 - \\ Seropédica, RJ - Brasil. \\ ${ }^{3}$ Universidade Federal de Santa Maria/CCR - Depto. de \\ Solos, Av. Roraima, 1000 - 97105-900 - Santa Maria, RS \\ - Brasil. \\ ${ }^{4}$ Embrapa Clima Temperado, BR 392, km 78, C.P. 40 - \\ 96010-971 - Pelotas, RS - Brasil. \\ *Corresponding author <ester.schiavon@ufpel.edu.br>
}

Edited by: Fernando Dini Andreote

Received February 19, 2019

Accepted July 15, 2019
ABSTRACT: Little is known about the interaction between the inoculation of diazotrophic bacteria, the variety, and the substrate used in inoculated sugarcane seedling production. Bearing this in mind, the aim of this study was to evaluate the effects of diazotrophic bacteria inoculation, four sugarcane varieties and four different substrates on the growth and nitrogen accumulation of sugarcane seedlings. Parameters related to sprouting, height, and root growth, as well as nitrogen accumulation, were evaluated. The results indicate that inoculating sugarcane seedlings belonging to the following varieties: RB867515, RB92579, RB966928 and RB975932 with bacteria may increase sprouting speed index, height, root length, fresh and dry matter weight, as well as nitrogen accumulation, which has resulted in a more uniform stem diameter. However, the responses to inoculation differ from variety to variety and are also dependent on the substrate used with better results observed in the commercial substrate and the substrate mixtures containing a higher proportion of organic compost. Understanding the interaction between the variety and the substrate with the bacterial inoculation is essential to the success of the production of inoculated sugarcane seedlings.

Keywords: Saccharum sp., carbonized rice husk, organic compost, biological nitrogen fixation

\section{Introduction}

Brazil is the world's largest producer of sugarcane (Saccharum sp.), and accounts for more than $25 \%$ of global production, with an area under cultivation of approximately 8.7 million hectares (IBGE, 2017). One of the major problems of sugarcane cultivation is conventional planting since this practice involves the use of approximately $18 \mathrm{t}$ of stems per hectare. One alternative is the utilization of pre-sprouted sugarcane seedlings, since this planting technology requires only one bud for seedling production and reduces the volume of propagating material applied by $90 \%$ (Oliveira et al., 2018). Furthermore, since seedlings have superior growth potential and a high tillering rate, they contribute to better control of invasive vegetation, which reduces the costs of crop management (Pereira et al., 2013). In addition, it is important to select a good substrate that should provide all the conditions necessary for healthy vegetative growth, and in particular, ensure the proper development of roots, as this is a determining factor in sugarcane survival after field transplantation (Asaduzzaman et al., 2015).

The association of diazotrophic bacterial species with sugarcane is known for their beneficial effects on promoting plant growth in different ways, especially through nitrogen-fixing and the production of phytohormones and siderophores, inorganic phosphate solubilization, and improving the resistance of plants to pathogens (Spaepen et al., 2007). Studies have shown that inoculating sugarcane seedlings with associative plant-growth-promoting bacteria increases sugarcane growth and yield, and improved disease resistance (Gírio et al., 2015), as well as increasing bud sprout rate and root emission, which is beneficial to seedling production (Chaves et al., 2015).

However, little is known about the interaction between the diazotrophic bacteria inoculation, the variety, and the substrate used, which may be the key to the success of inoculated sugarcane seedling production. Therefore, this study aimed to evaluate the effects of inoculation, four sugarcane varieties and four different substrates on the rapid securing of growth and nitrogen accumulation in sugarcane seedlings, targeting a crop stand establishment and increases in plant growth and productivity.

\section{Materials and Methods}

\section{Location and experimental design}

The experiment was carried out in a protected environment in the municipality of Pelotas, Rio Grande do Sul, Brazil, 52 ${ }^{\circ} 26^{\prime} 25^{\prime \prime} \mathrm{W}$ and $31^{\circ} 40^{\prime} 41^{\prime \prime} \mathrm{S}$, at an altitude of $60 \mathrm{~m}$ a.s.l. The greenhouse where the work took place was made of alveolar polycarbonate, and had a gable roof measuring $12.8 \mathrm{~m} \times 12 \mathrm{~m}$. More antechamber access was located in front of the greenhouse, totaling $165.6 \mathrm{~m}^{2}$. The on-site temperature was managed through a cooling system, ventilators, and the use of shading screens, and the temperature was maintained between 25 and $28{ }^{\circ} \mathrm{C}$. A system of floating trays and micro-sprinklers provided irrigation.

We used a randomized complete design (RCD), with three replicates. Each experimental unit was represented by a tray containing 54 plants in individualized tubes with a volume of $180 \mathrm{~cm}^{3}$. The factors were arranged in a trifactor scheme $(4 \times 4 \times 2)$, totaling 32 treatments. 
Four commercial sugarcane varieties (Saccharum sp. hybrids) were used, namely medium-late cycle RB867515 and RB92579, and early cycle RB966928 and RB975932. As regards the diazotrophic bacteria, the treatments administered were as follows: control (without inoculation), and mixed inoculation with five strains. The substrates consisted of three combinations of carbonized rice husk ( $\mathrm{CRH})$ with organic compost $(\mathrm{OC})$, in concentrations of 25,50 , and $75 \%$, respectively, as well as a commercial substrate.

\section{Substrates}

Organic compost used to prepare the substrates was produced from the composting of household waste, vegetables, cattle manure, litter swabs, rock dust, and sawdust. The maturation of the organic compost took approximately two months. The rice husk was charred and then washed, and the two materials were mixed on a volume basis, until the proportions stipulated for each of the treatments were reached (i.e. 25, 50, and $75 \%$ ). These substrates are referred to as 75CRH25OC $175 \%$ carbonized rice husk, $25 \%$ organic compost), 50CRH50OC (50\% carbonized rice husk, $50 \%$ organic compost), and 25CRH75OC (25\% carbonized rice husk, $75 \%$ organic compost). Additionally, we used a commercial substrate. Before the start of the experiment, chemical and physical analyses of the substrates were performed, and the results are shown in Table 1. Volumetric density, water retention capacity and porosity were analyzed according to the methodology described by Fermino (2014). Moisture content was identified by the standard method. The $\mathrm{pH}$ was determined in a 1: 5 dilution substrate solution being read at a benchtop $\mathrm{pH}$ and organic matter content, ash content and quantification of the macronutrients were determined following the procedure described by Abreu (2007).

\section{Seedling production and inoculation}

For the seedling production, small stalks, i.e. stem segments with individualized buds, were used, following the methodology developed in India by ICRISAT (2009). The material was taken from the median region of stems of ten month old plants. After being cut, the small stalks were cleaned, and were subjected to thermotherapy was for $30 \mathrm{~min}$ at $52{ }^{\circ} \mathrm{C}$. Subsequently, treatment with systemic fungicide based on pyraclostrobin was applied for $3 \mathrm{~min}$, and stalks under the inoculation treatment were then inoculated with a mixture of diazotrophic bacteria containing the following: Gluconacetobacter diazotrophicus BR11281 $=$ PAL $-5^{\mathrm{T}}$, described by Cavalcante and Döbereiner (1988); Herbaspirillum seropedicae BR11335 = HRC54, described by Baldani et al. (1986); H. rubrisubalbicans BR11504 = HCC103, described by Baldani et al. (1996); Paraburkholderia tropica - BR11366 ${ }^{\mathrm{T}}=\mathrm{PPe} 8^{\mathrm{T}}$, previously belonging to the genus Burkholderia, described by Reis et al. (2004) and recently reclassified by Oren and Garrity (2015); and Nitrospirillum amazonense BR11145 = CBAMc, previously belonging to the genus Azospirillum, described by Magalhães et al. (1983) and reclassified by Lin et al. (2014). These bacteria had been previously tested and selected by Oliveira et al. (2002, 2006) with monitoring of their population during the development of sugarcane seedlings and were provided by the Diazotrophic Bacteria Collection of Embrapa Agrobiologia - CBR Johanna Döbereiner.

The inoculation medium was produced at Embrapa Agrobiologia with each bacterial strain being individually cultured in a DYGS culture medium (Baldani et al., 2014). Once the purity had been confirmed, a complete colony was inoculated in $5 \mathrm{~mL}$ of DYGS medium and grown in a rotary shaker at $150 \mathrm{rpm}$ and $30{ }^{\circ} \mathrm{C}$ for $48 \mathrm{~h}$. Subsequently, $1 \mathrm{~mL}$ of the culture was transferred to $75 \mathrm{~mL}$ DYGS medium for culturing with the same conditions for approximately $24 \mathrm{~h}$ until a population density of $10^{8}$ cells $\mathrm{mL}^{-1}$ had been reached, which was measured using the Neubauer counting method. The inoculant counts and plant population after the tube phase were performed using the most probable number technique, as described by Baldani et al. (2014), with four semi-solid N-free media, LGI-P, JNFb, LGI, and JMV, suggested $G$. diazotrophicus, Herbaspirillum sp., $N$. amazonense, and $P$. tropica, respectively. After this, $175 \mathrm{~mL}$ of each strain was added to neutralized sterile peat to produce $250 \mathrm{~g}$ inoculant per strain.

A mixture of the inoculants was produced for inoculation as described by Santos et al. (2017). The five inoculum packages contained 108 bacterial cells $\mathrm{g}^{-1}$ peat before planting $(1,250 \mathrm{~g})$ diluted in $50 \mathrm{~L}$ of water and the small stalks were immersed in the solution for $30 \mathrm{~min}$. After this procedure, the small stalks were planted in tubes with a volume of $180 \mathrm{~cm}^{3}$, containing substrate. The tubes were kept in a greenhouse for the sprouting of buds and growth of seedlings.

Table 1 - Analysis of carbon $(C)$, nitrogen $(N)$, phosphorus $(P)$, potassium (K), calcium (Ca), magnesium, $(\mathrm{Mg}), \mathrm{C}: \mathrm{N}$ ratio, $\mathrm{pH}$, moisture $(\mathrm{M})$, organic matter (OM), ashes (A), water-holding capacity (WHC), volumetric density (VD), and total porosity (TP) of substrates formulated by mixtures of carbonized rice husk (CRH) and organic compost (OC) at three concentrations (25,50, $75 \%$ ), and a commercial substrate.

\begin{tabular}{|c|c|c|c|c|c|c|c|c|c|c|c|c|c|c|}
\hline Substrate & C & $\mathrm{N}$ & P & K & $\mathrm{Ca}$ & $\mathrm{Mg}$ & C:N & $\mathrm{pH}$ & M & $\mathrm{OM}$ & A & WHC & VD & TP \\
\hline & & & $-\mathrm{g}$ & -1 & & & & & & & & - & & \\
\hline Commercial & 268.00 & 6.40 & 0.34 & 2.20 & 2.19 & 1.02 & $42: 1$ & 6.48 & 40 & 78 & 22 & 42 & 63 & 46 \\
\hline $75 \mathrm{CRH} 250 \mathrm{C}$ & 267.19 & 3.39 & 0.71 & 3.56 & 1.53 & 0.93 & 79:1 & 5.33 & 47 & 51 & 49 & 21 & 43 & 78 \\
\hline 50CRH500C & 263.30 & 5.53 & 0.59 & 3.50 & 5.69 & 1.69 & $63: 1$ & 6.18 & 39 & 43 & 57 & 23 & 47 & 72 \\
\hline 25CRH750C & 259.41 & 7.68 & 0.47 & 3.45 & 9.86 & 2.44 & $47: 1$ & 5.59 & 27 & 51 & 49 & 27 & 53 & 66 \\
\hline
\end{tabular}




\section{Assessment of seedling characteristics and statistical analysis}

After the small stalks were planted, we recorded the number of seedlings sprouted, with aerial parts formed, every three days, until the $20^{\text {th }}$ day, when emergence of seedlings stabilized, to determine the emergence speed index (ESI), referred to in this study as the sprouting speed index (SSI). This was calculated using the formula proposed by Maguire (1962): SSI $=\mathrm{E} 1 / \mathrm{N} 1+\mathrm{E} 2 / \mathrm{N} 2+$ ... En / Nn where: SSI = sprout velocity index; E1, E2, $\ldots \mathrm{En}=$ number of normal seedlings recorded in the first count, in the second count, and in the last count; N1, $\mathrm{N} 2, \ldots \mathrm{Nn}=$ number of days since sowing at the first, second, and last count.

At the end of 30 days, nine plants were selected at random in each treatment for seedling evaluations. The height and root length $(\mathrm{cm})$ were measured with a ruler, while the stem diameter $(\mathrm{mm})$ was measured using a pachymeter in the median region of the first node formed. Fresh matter (g) was determined using a precision scale (accurate to $0.01 \mathrm{~g}$ ), and then the seedlings were packed in paper bags and taken to the greenhouse, where they remained for $24 \mathrm{~h}$ at a temperature of $60{ }^{\circ} \mathrm{C}$ for drying and subsequent evaluation of the dry matter. For the evaluation of total nitrogen $(\mathrm{g})$, the dried plants went through a $2 \mathrm{~mm}$ mesh of a knife mill, and the amount of nitrogen was determined by analyzing the solid plant tissue in a Perkin-Elmer Elementary Analyzer (world standard). This technique is based on the Pregal and Dumas method, where samples are burned in a pure oxygen environment, and the gases resulting from this combustion are carried by high purity helium (an inert gas) to the detection zone (Kaiser, 1970).

A statistical analysis was conducted using the SAS (Statistical Analysis System, version 8.2). The data obtained were analyzed for normality by the ShapiroWilk test. Homoscedasticity was evaluated using the Hartley test, and the independence of the residuals was verified graphically. Subsequently, the data were submitted to analysis of variance (ANOVA), and in the case of statistical significance $(p \leq 0.05$ and $p \leq 0.01)$, the effects of the varieties and the substrates were compared using the Tukey test, and the effects of the inoculation were compared using the test.

\section{Results}

With the application of the F test in the ANOVA, we found significant interactions between sugarcane variety and inoculation and sugarcane variety and substrate. We also found that the responses of the different sugarcane varieties varied according to the substrate used in the production of seedlings.

In general, the sprouting speed index (Figure 1) differed between sugarcane varieties, with the highest values found in the RB975932 variety, followed by the RB966928 variety. However, inoculation with diazotrophic bacteria stimulated the SSI of both the
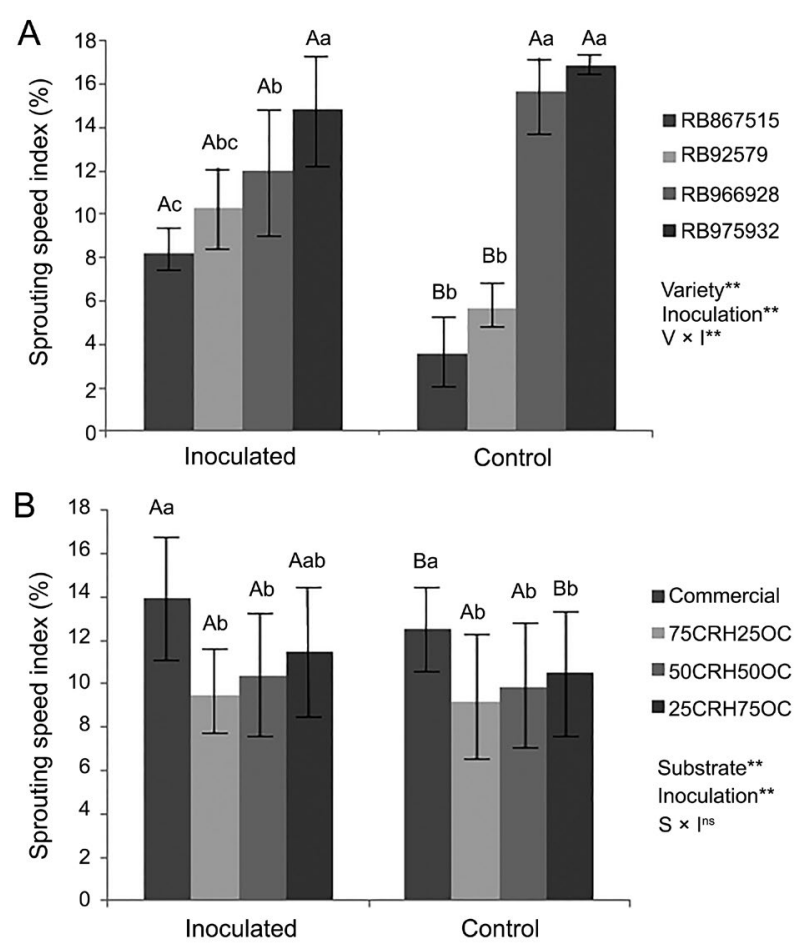

Figure 1 - Effects of the variety, substrate, and inoculation with diazotrophic bacteria on the sprouting speed index (SSI) in sugarcane seedlings. ns = Not significant; ${ }^{*}$ Significant at $1 \%$ probability. Bars followed by the same capital letter do not differ from each other, when comparing the inoculation treatment to their respective control in each variety $(A)$ or substrate $(B)$ using the $t$ test $(p \leq 0.05)$. Similarly, bars followed by the same lowercase letter do not differ from each other, when comparing varieties (A) and substrates (B) in inoculation treatments and controls by Tukey's test ( $p \leq 0.05)$. 75CRH250C: substrate composed of $75 \%$ carbonized rice husk (CRH) $+25 \%$ organic compost (OC); 50CRH500C: substrate composed of $50 \% \mathrm{CRH}+50 \%$ OC; 25CRH750C: substrate composed of $25 \% \mathrm{CRH}+75 \%$ OC.

RB867515 and RB92579 varieties, and the SSI was approximately $50 \%$ higher in inoculated seedlings, which reduced the sprouting difference between the four varieties tested.

With regard to the substrates, the SSI was higher when the commercial substrate was used, independent of the inoculation treatment. However, the commercial substrate, as well as the $25 \mathrm{CRH} 75 \mathrm{OC}$ substrate resulted in significant increases in shoot bud growth when used together with the inoculation with diazotrophic bacteria treatment.

As regards the evaluation of height (Figure 2), RB92579 and RB966928 responded positively to inoculation. Additionally, the latter was superior to the other varieties. It was also observed that the growth rate of the uninoculated (control) seedlings was greater when the commercial and 25CRH75OC substrates were used. However, when plants were inoculated with diazotrophic bacteria, there was no effect of any of the 
four substrates on plant height. As such, the interaction between the inoculation and the substrate led to the growth of more uniform seedlings.

The interaction between the inoculation and the substrate also resulted in greater uniformity with regard to the diameter of the stem of the seedlings (Figure 3), although this was not significant. For this parameter, there were isolated effects of the treatments, and an interaction effect between variety and inoculation. The response to inoculation was negative in quantitative terms, since the largest stem diameters were found in seedlings in the treatments without inoculation, and this was the case for all varieties and substrates tested. As regards the varieties, the largest stem diameters were recorded by RB975932, followed by RB92579 and as for the substrates, the commercial substrate, as well as the mixture containing $50 \%$ of organic compost, resulted in larger stem diameters in the seedlings.
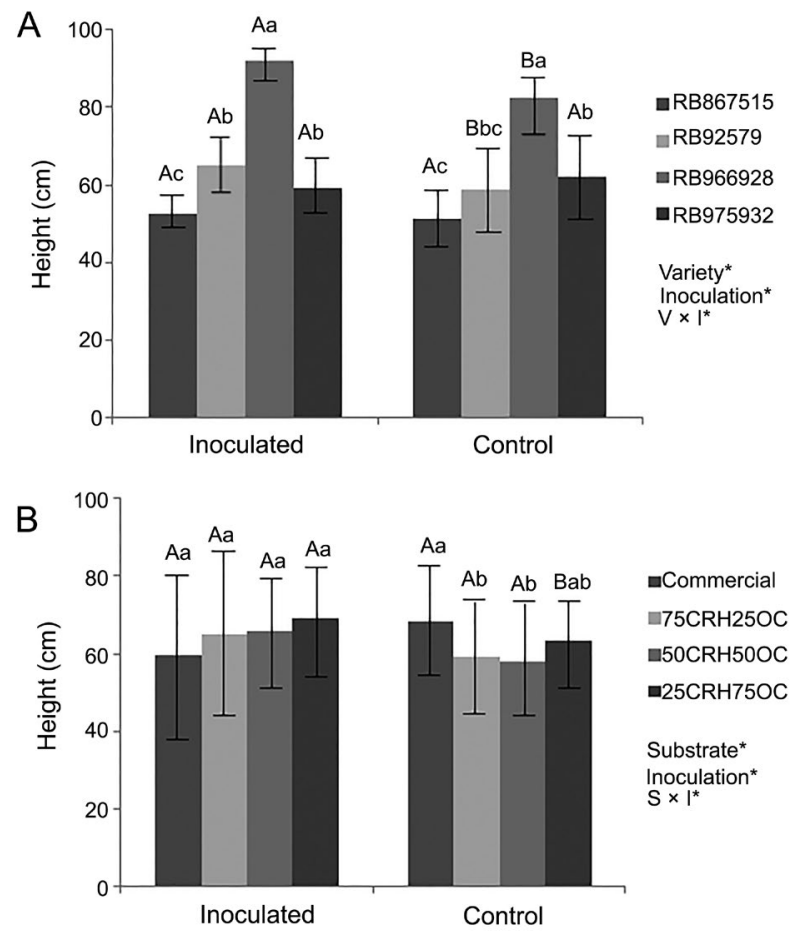

Figure 2 - Effect of the variety, substrate, and inoculation with diazotrophic bacteria on the height of sugarcane seedlings. * Significant at $5 \%$ probability. Bars followed by the same capital letter do not differ from each other, when comparing the inoculation treatment to their respective control in each variety $(A)$ or substrate (B) using the $t$ test $(p \leq 0.05)$. Similarly, bars followed by the same lowercase letter do not differ from each other, when comparing varieties (A) and substrates (B) in inoculation treatments and controls by Tukey's test ( $p \leq 0.05)$. 75CRH250C: substrate composed of $75 \%$ carbonized rice husk (CRH) $+25 \%$ organic compost (OC); 50CRH500C: substrate composed of 50 $\% \mathrm{CRH}+50 \%$ OC; $25 \mathrm{CRH} 750 \mathrm{C}$ : substrate composed of $25 \%$ $\mathrm{CRH}+75 \% \mathrm{OC}$.
When evaluating the root length (Figure 4), we found that all varieties had longer roots when they were inoculated with diazotrophic bacteria, irrespective of the substrate. The interaction between substrate and variety was significant at $1 \%$ probability. The best results were found for RB966928 and RB92579, with root lengths of approximately $32 \mathrm{~cm}$, and in the 50CRH50OC and commercial substrates, where the seedlings had root lengths of 34 and $30 \mathrm{~cm}$, respectively.

The total fresh matter of the seedlings (Figure 5) was higher in the inoculated varieties, except for RB975932, in which there was no difference in fresh matter between the treatments with and without inoculation. In RB867515 and RB966928, inoculation resulted in a $28 \%$ increase in the production of fresh matter, and for RB92579 the increase was $16 \%$. Inoculation also resulted in increases of 33 and $30 \%$ in the production of fresh matter of the seedlings grown in the 25CRH75OC and 75CRH25OC substrates. The results of the
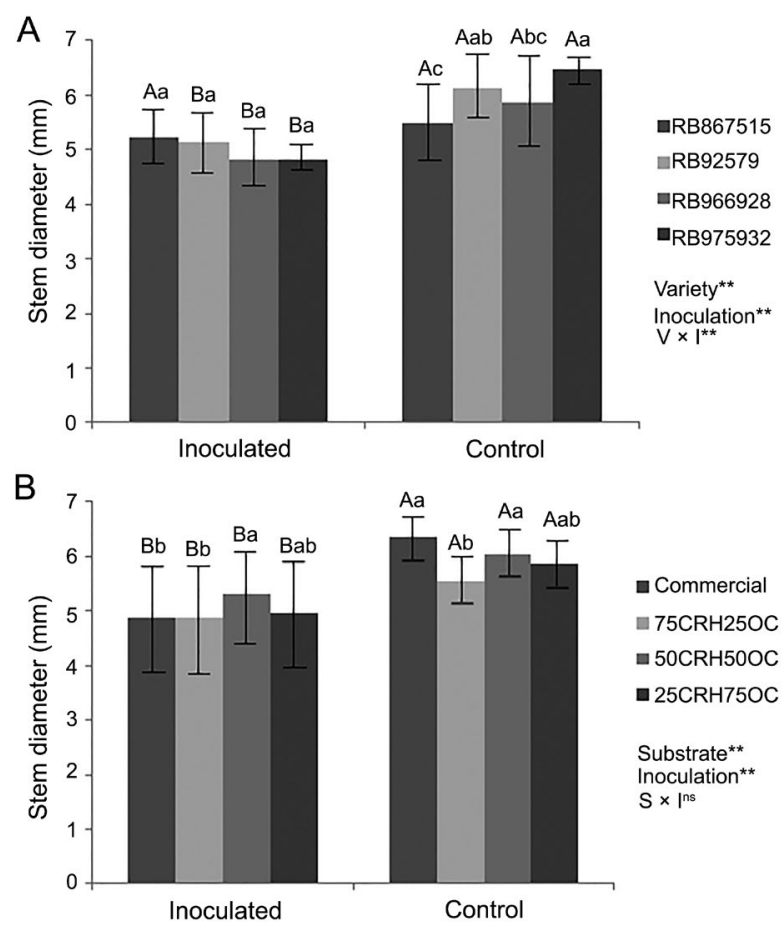

Figure 3 - Effect of the variety, substrate and inoculation with diazotrophic bacteria on the stem diameter in sugarcane seedlings. ns $=$ Not significant; ${ }^{*}$ * Significant at $1 \%$ probability. Bars followed by the same capital letter do not differ from each other, when comparing the inoculation treatment to their respective control in each variety (A) or substrate (B) using the test $(p \leq 0.05)$. Similarly, bars followed by the same lowercase letter do not differ from each other, when comparing varieties $(A)$ and substrates $(B)$ in inoculation treatments and controls by Tukey's test $(p \leq 0.05)$. 75CRH250C: substrate composed of $75 \%$ carbonized rice husk $(\mathrm{CRH})+25 \%$ organic compost (OC); 50CRH500C: substrate composed of $50 \% \mathrm{CRH}+50 \%$ OC; $25 \mathrm{CRH750C}$ : substrate composed of $25 \% \mathrm{CRH}+75 \% \mathrm{OC}$. 

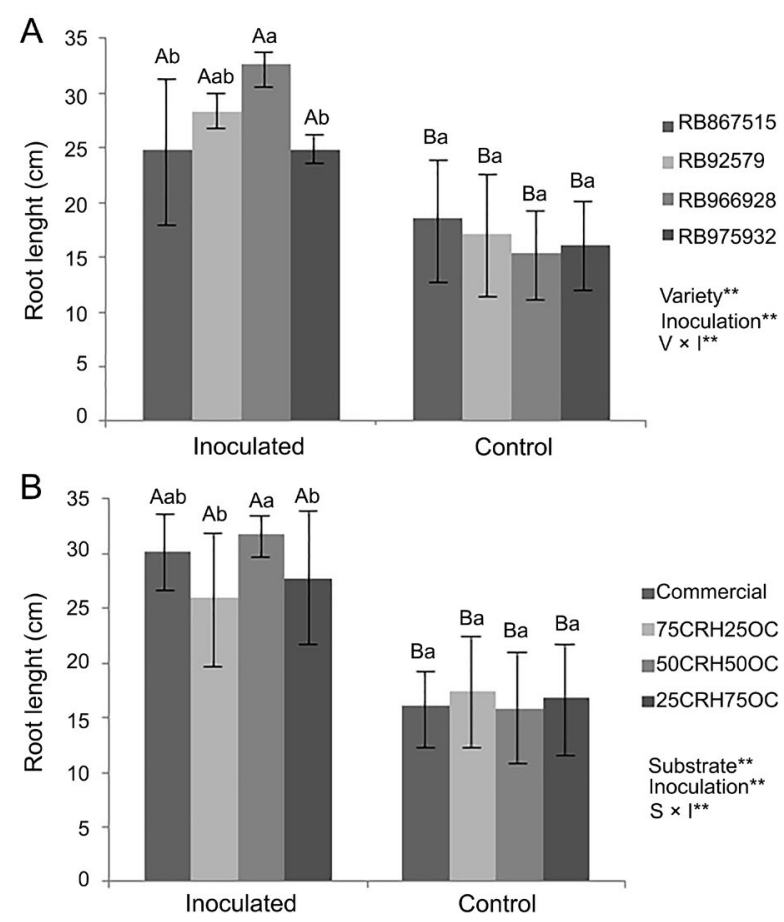

Figure 4 - Effect of the variety, substrate and inoculation with diazotrophic bacteria on the root length in sugarcane seedlings. ** Significant at $1 \%$ probability. Bars followed by the same capital letter do not differ from each other, when comparing the inoculation treatment to their respective control in each variety $(A)$ or substrate (B) using the t test $(p \leq 0.05)$. Similarly, bars followed by the same lowercase letter do not differ from each other, when comparing varieties $(A)$ and substrates $(B)$ in inoculation treatments and controls by Tukey's test ( $p \leq 0.05)$. 75CRH250C: substrate composed of $75 \%$ carbonized rice husk (CRH) $+25 \%$ organic compost (OC); 50CRH500C: substrate composed of $50 \%$ $\mathrm{CRH}+50 \%$ OC; $25 \mathrm{CRH} 750 \mathrm{C}$ : substrate composed of $25 \% \mathrm{CRH}$ $+75 \%$ OC.

dry matter analyses are shown in Figure 6. In the inoculation treatment, the dry weight of RB966928 was higher and did not differ from that of RB92579, but RB867515 was the only variety to respond positively to the inoculation, with an increase in dry matter of $85 \%$ compared to the control (uninoculated variety). As regards the substrates, the highest dry weight was found in uninoculated varieties grown in the commercial substrate. There were significant differences in dry weights of inoculated seedlings grown in the different substrates. The patterns with regard to the total nitrogen in the varieties (Figure 7) was similar, and inoculation with bacteria was beneficial only in the RB867515 variety. As regards the substrates, the commercial substrate resulted in seedlings with the highest nitrogen content, with and without inoculation with diazotrophic bacteria. However, inoculation, did not result in any significant difference between the nitrogen content of seedlings grown in the commercial substrate and those grown in the $25 \mathrm{CRH} 75 \mathrm{OC}$ substrate.
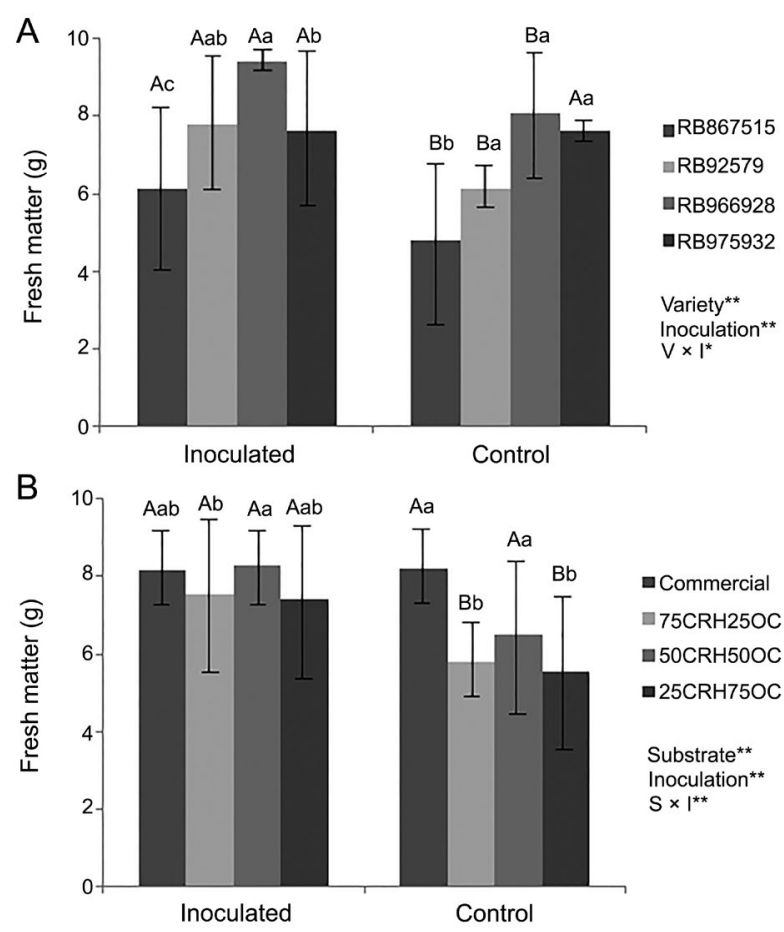

Figure 5 - Effect of the variety, substrate and inoculation with diazotrophic bacteria on the fresh matter in sugarcane seedlings. * and ${ }^{*}$ Significant at $5 \%$ and $1 \%$ probability, respectively. Bars followed by the same capital letter do not differ from each other, when comparing the inoculation treatment to their respective control in each variety $(A)$ or substrate $(B)$ using the t test $(p \leq 0.05)$. Similarly, bars followed by the same lowercase letter do not differ from each other, when comparing varieties (A) and substrates (B) in inoculation treatments and controls by Tukey's test ( $p \leq 0.05)$. 75CRH250C: substrate composed of $75 \%$ carbonized rice husk (CRH) $+25 \%$ organic compost (OC); 50CRH500C: substrate composed of $50 \% \mathrm{CRH}+50 \%$ OC; 25CRH750C: substrate composed of $25 \% \mathrm{CRH}+75 \%$ OC.

\section{Discussion}

Differences in sugarcane responses to inoculation with nitrogen fixing bacteria were expected due to the genetic characteristics of the varieties (Oliveira, 2006). Similarly, with regard to the sprouting of the buds, which is influenced by several factors, including temperature and humidity (Compagnon et al., 2017). However, what activates the organs of the bud and of the root primordia in the sugarcane stem are changes in the nutrient reserves due to the activity of enzymes and growth regulators (Casagrande and Vasconcelos, 2010). These enzymes and growth regulators are known to be produced by the diazotrophic bacteria used in this study. This also explains the differences in plant growth between the inoculation treatments, since the production of auxins, cytokinins, gibberellins, and ethylene by these bacteria promotes plant growth (Cassán et al., 2014). Effects on the initial development of sugarcane plants have also 


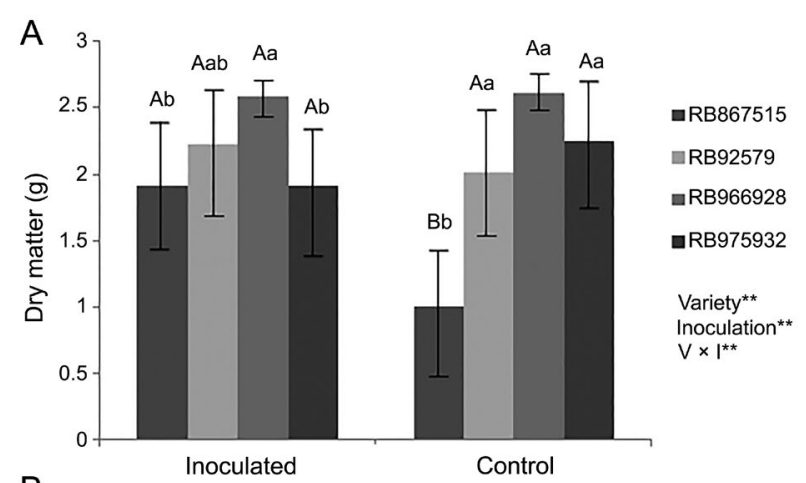

B

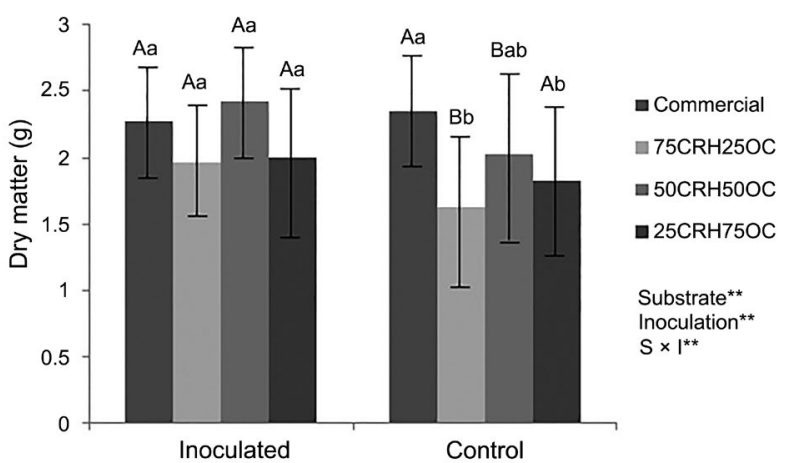

Figure 6 - Effect of the variety, substrate and inoculation with diazotrophic bacteria on the dry matter in sugarcane seedlings. ** Significant at $1 \%$ probability. Bars followed by the same capital letter do not differ from each other, when comparing the inoculation treatment to their respective control in each variety (A) or substrate (B) using the t test $(p \leq 0.05)$. Similarly, bars followed by the same lowercase letter do not differ from each other, when comparing varieties $(A)$ and substrates $(B)$ in inoculation treatments and controls by Tukey's test ( $p \leq 0.05)$. 75CRH250C: substrate composed of $75 \%$ carbonized rice husk (CRH) $+25 \%$ organic compost (OC); 50CRH500C: substrate composed of $50 \% \mathrm{CRH}+$ $50 \%$ OC; 25CRH750C: substrate composed of $25 \% \mathrm{CRH}+$ $75 \%$ OC.

been observed in other studies, and similar results of an increase in SSI in the RB867515 variety submitted to inoculation have been previously reported (SernaCock et al., 2011; Chaves et al., 2015). This change in seed sprouting speed is extremely desirable, especially in varieties of high economic importance, such as RB867515 and RB966928, which are the most commonly planted in Brazil (Gazaffi, et al., 2016).

The substrates used also influenced the sprouting of buds, since the period between sowing or planting and the emergence of seedlings is one of the critical phases of the plant cycle. During this phase, water is the main factor that influences the germination process and bud sprouting (Bradford, 1990), and should be available in appropriate abundance. We found that the highest sprouting rates, for most varieties, occurred in seedlings grown in the commercial substrate and in the mixture containing 75 $\%$ of organic compost (Figure 1). These materials have
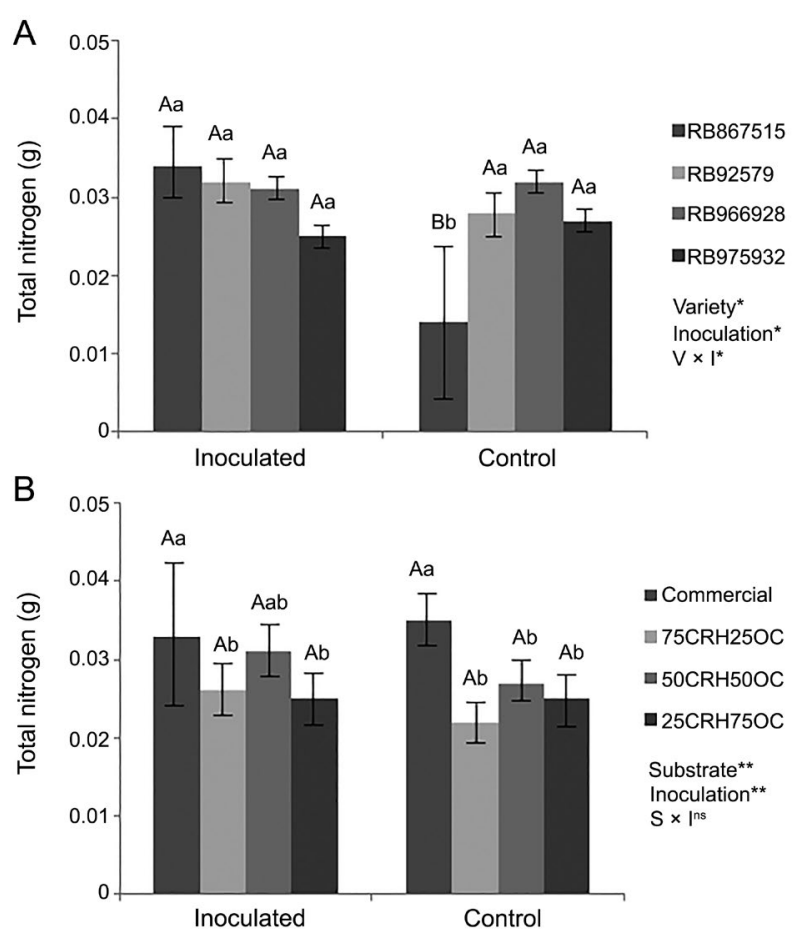

Figure 7 - Effect of the variety, substrate and inoculation with diazotrophic bacteria on the total nitrogen in sugarcane seedlings. ns Not significant. * and ${ }^{*}$ Significant at $5 \%$ and $1 \%$ probability, respectively. Bars followed by the same capital letter do not differ from each other, when comparing the inoculation treatment to their respective control in each variety $(A)$ or substrate (B) using the t test $(p \leq 0.05)$. Similarly, bars followed by the same lowercase letter do not differ from each other, when comparing varieties (A) and substrates (B) in inoculation treatments and controls by Tukey's test ( $p \leq 0.05)$. 75CRH250C: substrate composed of $75 \%$ carbonized rice husk (CRH) $+25 \%$ organic compost (OC); 50CRH500C: substrate composed of $50 \%$ $\mathrm{CRH}+50 \%$ OC; $25 \mathrm{CRH} 750 \mathrm{C}$ : substrate composed of $25 \% \mathrm{CRH}$ $+75 \%$ OC.

higher water retention (Table 1), promoting moisture availability for the stems during the process of sprouting the buds.

The carbonized rice husk in the mixtures is also important for bud sprouting, since it increases porosity and makes the substrate lighter, and reduces the resistance of the superficial layer to rupture by the primary sprouts (Cerqueira et al., 2015). According to Alphenaar (1993), it is important to look for porosity values between 75 and $90 \%$, since porosity determines the gas exchange and water movement in the container. A porosity value between 75 and $90 \%$ is a characteristic of substrates that contain a higher concentration of CRH (Table 1).

The biometric parameters of sugarcane seedlings produced from small stalks have been studied by several authors, since it is not yet known which parameter serves as a quality indicator for the seedlings. However, in sugarcane, it is important to analyze the potential 
for the accumulation of sucrose, which is related to the measurements of linear dimensions, such as height and diameter of the stem, which reflect the conditions of the root system (Sachdeva et al., 2011). As such, these parameters are important in the initial phase of seedling production.

The availability of nutrients is directly linked to the growth and development of shoot and roots, which explains the differences found between treatments with and without inoculation with diazotrophic bacteria, and between substrates. These bacteria, as previously mentioned, produce phytorials, such as auxin (Bashan and Holguin 1998; Taulé et al., 2012), which act on root growth. Increases in the length and surface of the roots of the plants also increase the absorption of water and nutrients present in the substrate (Taiz and Zeiger, 2013). This effect can be seen in Figure 4, where all inoculated varieties had a longer root length. The responses of the roots of the seedlings to the substrates also varied according to the variety of sugarcane, probably because each of the varieties had slightly different nutrient requirements, and each substrate had different nutrient availability (Table 1).

In treatments where the roots developed better, taller seedlings with higher fresh matter weights were also obtained (Figures 2 and 5). Within this scope, Oliveira et al. (2002), when inoculating sugarcane seedlings with different species of diazotrophic bacteria, isolated and mixed, observed that the combination of five species of bacteria resulted in a significant increase in the accumulation of fresh matter. Similarly, increases in shoot and root emissions were found by Figueiredo et al. (2013), in a study testing inoculation with diazotrophic bacteria and different substrates for the production of seedlings.

An additional factor is that the studies cited above emphasize that the responses of different sugarcane varieties to inoculation with nitrogen fixing bacteria are extremely variable, and when these responses are tested using different substrates, the results can vary even more. This is also supported by the results pertaining to the dry matter and total nitrogen content of the seedlings, as the only variety that responded to the inoculation with diazotrophic bacteria was RB867515. When not inoculated, this variety had the lowest accumulation of nitrogen, but when it was inoculated it had the largest accumulation of nitrogen. However, when not inoculated, variety RB867515 had the lowest dry matter content (Figure 6), and also had the shortest roots and lowest plant height. In other words, the general development of this variety was slower than that of the other varieties tested, but it was satisfactory compared with the results found by Chaves et al. (2015). The more pronounced response of RB867515 to the inoculation with bacteria was also observed in field experiments in which dry matter and total nitrogen were evaluated in sugarcane plants (Schultz et al., 2014, 2017).

The inoculation with bacteria also promoted an increase in dry matter in the seedlings grown in the 50CRH50OC and 25CRH75OC substrates (Figure 6). Figueiredo et al. (2013), however, when testing alternative substrates and a commercial one, concluded that only the latter is suitable for the production of inoculated sugarcane seedlings since the other materials are inert. This result corroborates the idea that the increase in biomass production in seedlings grown in the substrates formulated from a mixture of carbonized rice husk and organic compost may have occurred due to increases in the root lengths of seedlings induced by diazotrophic bacteria, which also increased the absorption of nutrients available in these materials. Therefore, substrates formulated from a mixture of carbonized rice husk and organic compost, as well as commercial substrate, may be suitable the production of inoculated seedlings.

This interaction between the diazotrophic bacteria and the alternative substrates is very positive under the current scenario, where it is necessary to produce more seedlings at a lower cost and with greater sustainability since this helps reduce both costs and the environmental impact of using nitrogen fertilizers.

\section{Conclusion}

Inoculating sugarcane seedlings with diazotrophic bacteria resulted in significant increases in the seedlings' growth and nitrogen accumulation in the four varieties studied. However, the responses to inoculation differed depending on the variety of sugarcane. Furthermore, the substrate used also influenced the response to inoculation and growth of sugarcane seedlings. We found that the most suitable substrates for inoculated sugarcane seedlings were the commercial substrate and the substrate mixtures containing 50 and $75 \%$ of organic compost. Our results confirm that it is essential to understand the interaction between the variety and the substrate with the diazotrophic bacteria for the successful production of inoculated sugarcane seedlings.

\section{Acknowledgments}

The authors would like to thank the Universidade Federal de Pelotas and the Coordenação de Aperfeiçoamento de Pessoal de Nível Superior (CAPES) / Brazil for the students' scholarships. In addition, significant consideration is given to Embrapa Clima Temperado for providing the space for the development of the work, and to Embrapa Agrobiologia for supplying the diazotrophic bacteria used in the research.

\section{Authors' Contributions}

Conceptualization: Matoso, E.S.; Reis, V.M.; Silva, S.D.A. Data analysis: Matoso, E.S.; Giacomini, S.J.; Silva, M.T. Design of methodology: Matoso, E.S.; Reis, V.M.; Silva, S.D.A. Writing and editing: Matoso, E.S.; Reis, V.M.; Silva, M.T.; Avancini, A.R.; Silva, S.D.A. 


\section{References}

Abreu, M.F; Abreu C.A; Sarzi I; Padua Junior, A.L. 2007. Water extracts for the chemical characterization of plant substrates. Horticultura Brasileira 25: 184-187 (in Portuguese, with abstract in English).

Alphenaar, A.P.; Pérez, C.M.; Lettinga, G. 1993. The influence of substrate transport limitation on porosity and methanogenic activity of anaerobic sludge granules. Applied Microbiology and Biotechnology 39: 276-280.

Asaduzzaman, M.; Saifullah; Mollick, S.R.; Hossain, M; Halim; Asao, T. 2015. Influence of Soilless Culture Substrate on Improvement of Yield and Produce Quality of Horticultural Crops. IntechOpen, London, UK.

Bashan, Y.; Holguin, G. 1998. Proposal for the division of plant growth-promoting rhizobacteria into two classifications: biocontrol-PGPB (plant growth-promoting bacteria) and PGPB. Soil Biology \& Biochemistry l: 1225-1228.

Baldani, J.I.; Baldani, V.L.D.; Seldin, L.; Döbereiner, J. 1986. Characterization of Herbaspirillum seropedicae gen. nov., sp. nov., a root-associated nitrogen-fixing bacterium. International Journal of Systematic and Evolutionary Bacteriology 36: 8693.

Baldani, J.I.; Pot, B.; Kirchhof, G.; Falsen, E.; Baldani, V.L.D.; Olivares, F.L.; Hoste, B.; Kersters, K.; Hartmann, A.; Gillis, M.; Döbereiner, J. 1996. Emended description of Herbaspirillum; inclusion of [Pseudomonas] rubrisubalbicans, a mild plant pathogen, as Herbaspirillum rubrisubalbicans comb. nov.; and classification of a group of clinical isolates EF group 1 as Herbaspirillum species 3. International Journal of Systematic and Evolutionary Bacteriology 46: 802-810.

Baldani, I.; Reis, V.M.; Videira, S.S.; Boddey, L.H.; Baldani, V.L.D. 2014. The art of isolating nitrogen-fixing bacteria from non-leguminous plants using $\mathrm{N}$-free semi-solid media: a practical guide for microbiologists. Plant and Soil 384: 413-431.

Bradford, K.J. 1990. A water relations analysis of seed germination rates. Plant Physiology 94: 840-849.

Cassán, F.; Vanderleyden, J.; Spaepen, S. 2014. Physiological and agronomical aspects of phytohormone production by model plant bacteria- promoting rhizobacteria (PGPR) belonging to the genus Azospirillum. Journal of Plant Growth Regulation. 33: 440-59.

Cavalcante, V.; Döbereiner, J. 1988. A new acid-tolerant nitrogen-fixing bacterium isolated from sugarcane. Plant and Soil 108: 23-31.

Cerqueira, F.B.; Freitas, G.A.; Maciel, C.J.; Carneiro, J.S.S.; Leite, R.C. 2015. Seedlings of tomato cv. Santa Cruz on different substrates. Journal of Bioenergy and Food Science 2: $39-45$.

Chaves, V.A.; Santos, S.G.; Schultz, N.; Pereira, W.; Sousa, S.J.; Monteiro, R.C.; Reis, V.M. 2015. Initial development of two sugarcane varieties inoculated with diazotrophic bacteria. Revista Brasileira de Ciência do Solo 39: 15951602.

Compagnon, A.M.; Silva, R.P.; Furlani, C.E.A.; Cavichioli, F.A.; Arriel, F.H. 2017. Operational uniformity for a sugarcane planter. African Journal of Agricultural 12: 953-962.
Fermino, M.H. 2014. Substrates: Composition, Characterization, and Methods of Analysis Substrates: Composition, Characterization, and Methods of Analysis = Substratos: Composição, Caracterização, e Métodos de Análise. Agrolivros, Guaíba, RS, Brazil (in Portuguese).

Figueiredo, G.G.O.; Lopes, V.R.; Filho, J.C.B.; Daros, E. 2013. Effect of substrates and plant growth promoting bacteria. Revista de Ciências Agrárias 36: 447-454.

Gazaffi, R.; Cursi, D.E.; Chapola, R.G.; Santos, J.M.; Fernandes Júnior, A.R.; Carneiro, M.S.; Barbosa, G.V.; Hoffmann, H.P. 2016. RB varieties: a major contribution to the sugarcane industry in Brazil. Available at: https://www.ridesaufscar.com. br/single-post/2016/12/05/RB-varieties-a-major-contribution-tothe-sugarcane-industry-in-Brazil [Accessed Aug 3, 2018]

Gírio, L.A.S.; Dias, F.L.F.; Reis, V.M.; Urquiaga, S.; Schultz, N.; Bolonhezi, D.; Mutton, M.A. 2015. Plant growth-promoting bacteria and nitrogen fertilization effect on the initial growth of sugarcane from pre-sprouted seedlings. Pesquisa Agropecuária Brasileira 50: 33-43 (in Portuguese, with abstract in English).

Instituto Brasileiro de Geografia e Estatística [IBGE]. 2017. Systematic Survey of Agricultural Production = Levantamento Sistemático da Produção Agrícola. IBGE, Rio de Janeiro, RJ, Brazil (in Portuguese).

International Crops Research Institute for the Semi-Arid Tropics [ICRISAT]. 2009. Sustainable Sugarcane Initiative: Training Manual. ICRISAT, Patancheru, India.

Kaiser, H. 1970. Report for analytical chemists. II. Quantitation in elemental analysis. Analytical Chemistry 4: 26-59.

Lin, S.Y.; Hameed, A.; Shen, F.T.; Liu, Y.C.; Hsu, Y.H.; Shahina, M.; Lai, W.A.; Young, C.C. 2014. Description of Niveispirillum fermenti gen. nov., sp. nov., isolated from a fermentor in Taiwan, transfer of Azospirillum irakense 1989 as Niveispirillum irakense comb. nov., and reclassification of Azospirillum amazonense 1983 as Nitrospirillum amazonense gen. nov. Antonie van Leeuwenhoek 105: 1149-1162.

Magalhães, F.M.; Baldani, J. I.; Souto, S.M.; Kuykendall, J.R.; Döbereiner, J. 1983. A new acid-tolerant Azospirillum species. Anais da Academia Brasileira de Ciências 55: 417-430.

Maguire, J.D. 1962. Speed of germination: aid in selection and evaluation for seedling emergence and vigor. Crop Science 2: 176-177.

Oliveira, A.L.M.; Urquiaga, S.; Döbereiner, J.; Baldani, J.I. 2002. The effect of inoculating endophytic $\mathrm{N}_{2}$-fixing bacteria on micropropagated sugarcane plants. Plant and Soil 242: 205-215.

Oliveira, A.L.M.; Canuto, E.L.; Urquiaga, S.; Reis, V.M.; Baldani, J.I. 2006. Yield of micropropagated sugarcane varieties in different soil types following inoculation with diazotrophic bacteria. Plant and Soil 284: 23-32.

Oliveira, H.P.; Melo, R.O.; Baldotto, M.A.; Andrade, M.A.A.; Baldotto, L.E.B. 2018. Performance of pre-sprouted sugarcane seedlings in response to the application of humic acid and plant growth-promoting bacteria. Semina: Ciências Agrárias 39: $1365-1370$.

Oren, A.; Garrity, G.M. 2015. Notification that new names of prokaryotes, new combinations, and new taxonomic opinions have appeared in volume 65, part 2, of the IJSEM. International Journal of Systematic and Evolutionary Microbiology 65: 1397-1399. 
Pereira, W.; Leite, J.M.; Hipólito, G.S.; Santos, C.L.R.; Reis, V.M. 2013. Biomass accumulation in sugarcane varieties inoculated with different strains of diazotrophs. Revista Ciência Agronômica 44: 363-370 (in Portuguese, with abstract in English).

Reis, V.M.; Estrada-de los Santos, P.; Tenorio-Salgado, S.; Vogel, J.; Stoffels, M.; Guyon, S.; Mavingui, P.; Baldani, V.L.D.; Schimid, M.; Baldani, J.I.; Balandreau, J.; Hartmann, A.; Caballero-Mellado, J. 2004. Burkholderia tropica sp. nov., a novel nitrogen-fixing, plantassociated bacterium. International Journal of Systematic and Evolutionary Bacteriology 54: 2155-2162.

Sachdeva, M.; Bhatia, S.; Batta, S.K. 2011. Sucrose accumulation in sugarcane: a potential target for crop improvement. Acta Physiologiae Plantarum 33: 1571-1583.

Schultz, N.; Silva, J.A.; Sousa, J.S.; Monteiro, R.C.; Oliveira, R.P.; Chaves, V.A.; Pereira, W.; Silva, M.F.; Reis, V.M.; Urquiaga, S. 2014. Inoculation of sugarcane with diazotrophic bacteria. Revista Brasileira de Ciência do Solo 38: 359-371.
Schultz, N.; Pereira, W.; Silva, P.A.; Baldani, J.I.; Boddey, R.M.; Alves, B.J.R.; Urquiaga, S.; Reis, V.M. 2017. Yield of sugarcane varieties and their sugar quality grown in different soiltypes and inoculated with a diazotrophic bacteria consortium, Plant Production Science 20: 366-374.

Serna-Cock, L.; Arias-García, C.; Hernandez, L.J.V. 2011. Effect of biofertilization on the growth of potted sugarcane plants (Saccharum officinarum). Biotecnologia em el Sector Agropecuario y Agroindustrial 9: 85-95.

Spaepen, S.; Vanderleyden, J.; Remans, R. 2007. Indole-3-acetic acid in microbial and microorganism-plant signaling. FEMS Microbiology Reviews 31: 425-448.

Taiz, L.; Zeiger, E. 2013. Plant Phisiology. 5ed. Artmed, Porto Alegre, RS, Brazil.

Taulé, C.; Mareque, C.; Barlocco, C.; Hackembruch, F.; Reis, V.M.; Sicardi, M.; Battistoni, F. 2012. The contribution of nitrogen fixation to sugarcane (Saccharum officinarum L.), and the identification and characterization of part of the associated diazotrophic bacterial community. Plant and Soil 356: 35-49. 